\title{
POLÍTICAS PÚBLICAS PARA A SUSTENTABILIDADE EM AMBIENTES DE MONTANHA NO BRASIL
}

\author{
A. López Netto ${ }^{1 *}$; R.L.Assis ${ }^{2}$ \\ 1 Programa de Pós-graduação Ciência, Tecnologia e Inovação Agropecuária, Universidade Federal Rural do Rio \\ de Janeiro - Embrapa Agrobiologia - Núcleo de Pesquisa e Treinamento de Agricultores de Nova Friburgo \\ (NPTA), 23891-000, Seropédica-RJ, Brasil \\ 2 Pesquisador, Embrapa Agrobiologia - NPTA, 23891-000, Seropédica-RJ, Brasil
}

* amazile.lopez.n@gmail.com

Artigo submetido em 17/08/2015 e aceito em 25/08/2015

\section{RESUMO}

As montanhas apresentam grande diversidade biológica, essencial para a sobrevivência do ecossistema no planeta, e fornecem recursos fundamentais para o ser humano, como a água e depósitos genéticos para a segurança alimentar. O Brasil encontra-se entre os países que apresentam maior área de montanhas do planeta; sendo signatário de documentos elaborados em convenções ambientais globais, em que o fomento a sustentabilidade em ambientes de montanha é firmado; tendo-se como exemplos, a Agenda 21 Global; Plano de Aplicação das Decisões da Conferência Mundial sobre Desenvolvimento Sustentável; e O Futuro que Queremos. O objetivo deste trabalho é analisar se as ações públicas brasileiras
\end{abstract}

promovem a sustentabilidade em ambientes de montanha, conforme preconizado nas convenções ambientais globais. Isto foi realizado através de levantamento e análise crítica de dados secundários, onde se observou que o governo brasileiro não apresenta ações públicas onde o tema focal sejam as montanhas, verificando-se apenas temas transversais a nível federal, regional e estadual que atingem esses ambientes. Dentre essas políticas, destaca-se o pagamento por serviços ambientais que poderá ser base de reflexão para ações públicas que fomentem o desenvolvimento rural sustentável nos ambientes de montanha brasileiros.

PALAVRAS-CHAVE: Ação pública, desenvolvimento rural sustentável, pagamento por serviços ambientais.

\section{PUBLIC POLICIES FOR SUSTAINABILITY IN MOUNTAIN ENVIRONMENTS IN BRAZIL}

\begin{abstract}
The mountains encompass a great biological diversity, essential to the survival of the ecosystem on the planet, and key resources for humans, such as water and deposits for genetic food safety. Brazil is among the countries with largest area of mountains on the planet. The country is a signatory of documents prepared for global environmental conventions, in which the fostering sustainability in mountain environments is signed, taking as examples Global Agenda 21; Plan of Implementation of the World Summit on Sustainable Development, and The Future We Want. The objective of this study is to analyze whether the Brazilian public actions promoting
\end{abstract}

sustainability in mountain environments, as recommended in the global environmental conventions. This was done through a survey and critical analysis of secondary data, where it was observed that the Brazilian government has no public actions where the focal theme are the mountains, checking only transversal issues at the federal, regional and state levels that affect these environments. Among these policies, there is the payment for environmental services that can be basis for considering public actions that promote sustainable rural development in mountain environments Brazilians.

KEYWORDS: Policies; sustainable rural development; payments for environmental services. 


\section{INTRODUÇÃO}

Os ecossistemas de montanha ocupam, aproximadamente, a quarta parte da superfície terrestre e são a base direta de sustento de quase $12 \%$ da população mundial, proporcionando bens e serviços básicos para mais de 50\% da humanidade (NAÇÕES UNIDAS, 2009).

Aproximadamente $10 \%$ da população mundial vivem em áreas montanhosas de altas encostas e cerca de $40 \%$ da humanidade ocupam as áreas de bacias hidrográficas que se localizam nas baixas e médias montanhas (NAÇÕES UNIDAS, 1992).

Os ambientes de montanha são importantes locais de lazer, esporte, turismo (UNEPWCMC, 2002) e centros de patrimônio étnico, cultural e com significado espiritual para várias sociedades (MILLENIUM ECOSYSTEM ASSESSMENT, 2005).

Convenções ambientais globais preconizam políticas públicas para a sustentabilidade em ambientes de montanha. A partir da Agenda 21 Global, capítulo 13, denominado "Gerenciamento de Ecossistemas Frágeis: Desenvolvimento Sustentável das Montanhas", as Nações Unidas, principalmente através da Food and Agriculture Organization (FAO), incentivam a reflexão das lideranças de países de todos os continentes sobre a sustentabilidade em ambientes de montanha (NAÇÕES UNIDAS, 2009).

O capítulo 13 da Agenda 21 Global (NAÇÕES UNIDAS, 1992) orienta que os países desenvolvam políticas oferecendo incentivos a agricultores e habitantes locais para que adotem medidas conservacionistas e tecnologias apropriadas aos ambientes de montanha. O pagamento por serviços ambientais (PSA) é um dos mecanismos que pode ser utilizado para seguir essa orientação.

O objetivo deste trabalho é analisar se as ações públicas brasileiras promovem a sustentabilidade em ambientes de montanha, conforme recomendado nas convenções ambientais globais.

As montanhas apresentam ambientes com características próprias, como, declividade e altitude, que determinam grande variabilidade de ambientes com certa proximidade, além de produzirem considerável quantidade de recursos hídricos, sendo dessa forma, importantes na produção de serviços ambientais. O Brasil encontra-se entre os vinte países que apresentam a maior área montanhosa do planeta, considerando-se as altas, médias e baixas montanhas (UNEP-WCMC, 2002). Cultivos de café, citros, maçã, uva, olericultura, e pecuária leiteira, representam exemplos de sucesso de atividades agropecuárias praticadas nas montanhas brasileiras. Porém, ações antrópicas inadequadas podem provocar a degradação desses ambientes, como desmatamento e degradação do solo. As organizações governamentais brasileiras, de forma geral, não perceberam a importância de trabalhar os ambientes de montanha em contexto integrado, criando condições para que as populações que vivem em regiões montanhosas do país tenham qualidade de vida, assim como as comunidades de terras baixas que dependem de recursos fornecidos pelas terras altas, como, por exemplo, a água. É necessária a implantação no Brasil de políticas públicas direcionadas especificamente aos ambientes de montanha, possibilitando assim, o desenvolvimento sustentável dessas regiões.

\section{MATERIAIS E MÉTODOS}

O estudo foi realizado através de levantamento e análise crítica de dados secundários, obtidos através de pesquisa bibliográfica e documental, que foi realizada a partir de artigos de periódicos científicos, livros, teses, relatórios técnicos e legislação (GIL, 2010). 
Inicialmente, define-se o que são ambientes de montanha, apresentando suas características intrínsecas, fornecendo assim base para a discussão de políticas públicas adequadas ao desenvolvimento rural sustentável dessas regiões. A seguir se estabelece discussão sobre desenvolvimento rural e sustentabilidade, conceitos que geram divergências de opinião, mas que são utilizados em documentos elaborados em convenções ambientais globais. Logo após apresentam-se as convenções mais relevantes para o tema sustentabilidade em ambientes de montanha, e a atuação do Brasil nesse contexto. Também, definem-se "políticas públicas", enfatizando-se "policies"/"ação pública"; para então analisar ações públicas brasileiras direcionadas aos ambientes de montanha.

Observa-se que apesar da inexistência de ações públicas específicas para os ambientes de montanha brasileiros; existem programas focados em temas transversais, como o pagamento por serviços ambientais (PSA), que atingem esses ambientes. Em programas de PSA, o manejo e a conservação do solo e da água se fazem presentes, como um dos condicionantes para que o produtor rural seja remunerado. Em ambientes de montanha práticas conservacionistas são essenciais para sua sustentabilidade, possibilitando assim, a continuidade de fornecimento de produtos vitais para a humanidade, como por exemplo, a água.

\section{RESULTADOS E DISCUSSÃO}

\subsection{Ambientes de montanha e suas particularidades}

Existem várias definições para montanha. Neste trabalho entende-se montanha conforme classificação de Kapos et al (2000), utilizada pelas Nações Unidas através da United Nations Environment Programme - World Conservation Monitoring Centre, (UNEP-WCMC, 2002) e o Millenium Ecosystem Assessment (2005). De acordo com essa classificação, os ambientes de montanha são definidos pelos critérios de altitude, relevo relativo e declividade, sendo que acima de 2.500 metros é considerada apenas altitude (Tabela 1). A partir dessa definição, 27\% da superfície terrestre são consideradas área de montanha.

O Brasil encontra-se entre os quatro países com maior área de montanhas na América Latina. No Brasil, as regiões com altitudes iguais ou superiores a 600 metros representam 16,91\% $\left(1.439 .838 \mathrm{~km}^{2}\right)$ do território nacional (CRESCENTE FÉRTIL, 2002).

Tabela 1- Classificação de Kapos et al. (2000) relacionando as montanhas com altitude, altura e declividade.

\begin{tabular}{|l|l|l|l|}
\hline Classe & $\begin{array}{l}\text { Altitude } \\
(\text { metros })\end{array}$ & Altura (relevo relativo) & Declividade \\
\hline 1 & Acima de 4.500 & Não considerada & Não considerada \\
\hline 2 & $3.500-4.500$ & Não considerada & Não considerada \\
\hline 3 & $2.500-3.500$ & Não considerada & Não considerada \\
\hline 4 & $1.500-2.500$ & Não considerada a $2^{\circ}(4,5 \%)$ \\
\hline 5 & $1.000-1.500$ & $\begin{array}{l}\text { Declividade } \geq \text { a } 5^{\circ}(11 \%) \quad \text { ou altura }>300 \text { metros, } \\
\text { considerando raio de } 7 \mathrm{~km}\end{array}$ \\
\hline 6 & $300-1.000$ & Altura $>$ que 300 metros, considerando raio de $7 \mathrm{~km}$ \\
\hline
\end{tabular}

Fonte: UNEP-WCMC, 2002; MILLENIUM ECOSYSTEM ASSESSMENT, 2005. 
Da mesma forma que existem várias definições para montanha, há para o termo ambiente, que pode ser definido como uma "visão das relações complexas e sinérgicas gerada pela articulação dos processos de ordem física, biológica, termodinâmica, econômica, política $e$ cultural" (BOEIRA, 2002). Para Correa (2008) o ambiente é dinâmico, abrange e interage com o ser humano. Já Dulley (2004) observa que ambiente é a natureza conhecida pelo ser humano e que deve ser relacionado ao espaço e ao tempo. Enquanto Brailovsky e Foguelman (1997) definem ambiente como o resultado das interações entre sistemas ecológicos e socioeconômicos, suscetíveis a provocarem efeitos sobre os seres vivos e as atividades humanas.

Devido às distintas definições e classificações de montanha e ambiente, será considerada a seguinte definição para ambientes de montanha: a classificação para montanhas de Kapos et al. (2000), como base conceitual e a definição de ambiente como as interações dinâmicas dos sistemas ecológicos com os sistemas econômico, político, cultural, espiritual e social, relacionando espaço e tempo. Portanto "ambientes de montanha" são áreas, onde estão localizadas montanhas - de classes 1 a 6 - onde comunidades humanas estão presentes, considerando-se seus valores, expressões e atividades de forma geral em determinado contexto de tempo e o ambiente natural do entorno. Ressalta-se o conceito antropocêntrico dessa definição, onde o ser humano é considerado agente essencial no contexto.

Devido às características intrínsecas das montanhas, como altitude, declividade e altura relativa, esses ecossistemas apresentam grande diversidade biológica. As montanhas são ilhas ecológicas de endemismo por seu isolamento e verticalidade. De acordo com a Alianza para las Montañas (2010) e a UNEP-WCMC (2002), as montanhas são depósitos de diversidade genética.

Os ecossistemas de montanha são a base para as bacias hidrográficas e para a boa qualidade da água (MARTINELLI, 2007). Grande parte das nascentes localiza-se nas regiões altas do planeta. As montanhas são conhecidas como "torres de água". A descarga hídrica proveniente das montanhas pode contribuir de $32 \%$ a $95 \%$ da descarga total dos recursos hídricos de uma bacia (MESSERLI, DROZ, GERMANN, 2003). Além da contribuição das montanhas para a segurança alimentar da humanidade; sua grande diversidade biológica e ainda ser fornecedora de água; o ser humano usufrui de descanso e das atividades de lazer, esporte e turismo disponibilizados nas regiões montanhosas.

\subsection{Desenvolvimento rural e sustentabilidade}

Com o passar dos anos, os ambientes de montanha estão cada vez mais vulneráveis devido à demanda maior por água e por recursos naturais; aumento do turismo, mineração e agricultura inadequados; êxodo rural e as mudanças climáticas. Esses fatores representam problemas aos ambientes de montanha que necessitam de atenção urgente e esforços organizados para solucionálos. As Nações Unidas (2005) observam que cada vez mais países reconhecem a importância do desenvolvimento sustentável nas áreas de montanha para a erradicação da pobreza. O gerenciamento adequado dos recursos dos ambientes de montanha, visando à sustentabilidade e políticas públicas adequadas com o objetivo de promover o desenvolvimento rural sustentável se fazem necessárias (NAÇÕES UNIDAS, 1992).

Com a publicação do Relatório Brundtland, em 1987, surgiu uma definição para o conceito de desenvolvimento sustentável que é "desenvolvimento que atende às necessidades do presente sem comprometer a capacidade das gerações futuras de atender suas próprias necessidades" (COMISSÃO MUNDIAL SOBRE MEIO AMBIENTE E DESENVOLVIMENTO, 1991). Definição que gerou e ainda gera críticas e polêmicas (VEIGA, 2005, MATIAS e PINHEIRO, 
2007). Verifica-se, porém, que a definição de desenvolvimento sustentável comporta alguns elementos importantes. Como, por exemplo, o fato de que, para gerar sustentabilidade, é necessário combater a pobreza com o desenvolvimento econômico; um compromisso entre gerações; e a ideia de que o planeta dispõe de uma quantidade limitada de recursos e de uma capacidade limitada de dar condições à vida. Embora esses elementos, em conjunto, possam ser considerados como a corrente principal do desenvolvimento sustentável existe controvérsia sobre o tema. Isto porque, para alguns, o conceito de desenvolvimento sustentável é impreciso e comporta várias interpretações, muitas vezes carregadas de utopia, e que as várias teorias que o circunscrevem se correlacionam a ideologias políticas diferentes.

Muitas correntes ambientalistas aderiram ao movimento do desenvolvimento sustentável e inúmeras lhe fazem severas críticas por motivos variados. As correntes ecocêntricas apontam o fato de que o movimento é antropocêntrico no seu âmago e não representaria uma mudança profunda ou de espécie, na relação dos seres humanos com os demais seres vivos e elementos da natureza, mas apenas uma mudança de grau, caracterizando uma abordagem meramente reformista. Uma das maiores críticas vem do fato de ser esse movimento impulsionado pelas grandes empresas multinacionais, que antes haviam boicotado a proposta do ecodesenvolvimento; sinônimo de proposta que para Sachs (1993) postula uma visão solidária em longo prazo, abrangendo toda a humanidade. A ênfase nesse caso deve recair sobre os espaços de autonomia local, seu ponto de partida e lugar por onde deveriam passar obrigatoriamente os movimentos políticos para conduzir essa nova concepção de desenvolvimento. Certamente é um conceito com muitos defensores e críticos; e um tema sobre o qual não há acordo (MATIAS; PINHEIRO, 2008).

Apesar de todas as controvérsias o termo desenvolvimento sustentável continua sendo utilizado em convenções ambientais globais, assim como nos documentos elaborados a partir dessas reuniões, e nas políticas públicas de países de todos os continentes, inclusive sobre as montanhas. A questão do termo "desenvolvimento rural" também pode gerar controvérsias por causa do termo "rural", devido aos debates existentes sobre o que é rural e o que é urbano.

Existe na sociedade, de forma geral, uma associação do rural com a agricultura. Então a atividade agrícola torna-se a referência para qualificar o espaço rural. Mas é importante lembrar que o rural não se restringe a atividade agrícola. A ruralidade é um processo dinâmico com elementos da cultura local, com a incorporação de novos valores, hábitos e técnicas (CARNEIRO, 1998).

Portanto ao se analisar "desenvolvimento rural" neste trabalho, o foco será o rural nos ambientes de montanha, onde a agricultura é a atividade econômica principal, mesmo com a presença de outras atividades geradoras de emprego e renda, onde existe, portanto, pluriatividade.

Os ambientes de montanha proporcionam uma gama ampla de bens e serviços para toda a sociedade, consequentemente existindo uma interdependência das terras altas e baixas. A promoção da sustentabilidade das montanhas pode desempenhar uma importante função no benefício das terras baixas ao garantir o abastecimento adequado de água e alimento, estabilidade ambiental, conservação da biodiversidade, cultura, lazer, entre outros aspectos.

Para garantir a sustentabilidade dos ambientes de montanha é imprescindível reduzir a pobreza, a marginalidade e a desigualdade, pois considerações sociais desfavoráveis contribuem para a deterioração dos recursos naturais dos ecossistemas de montanha.

No mundo verifica-se um estado generalizado de pobreza e perda do conhecimento autóctone entre os habitantes das montanhas. Mas as Nações Unidas (2005) observam que cada vez mais países reconhecem a importância do desenvolvimento sustentável nas regiões montanhosas para a erradicação da pobreza. 


\subsection{Brasil e os ambientes de montanha no contexto das convenções ambientais globais}

De forma geral as convenções ambientais globais apresentaram em sua pauta as montanhas. Mas dentre essas convenções, algumas colocaram o tema montanhas em maior destaque: a Conferência das Nações Unidas sobre o Meio Ambiente e o Desenvolvimento, realizada em 1992 no Rio de Janeiro, conhecida como Rio 92; a Cúpula Mundial sobre Desenvolvimento Sustentável em Joanesburgo, na África do Sul, em 2002, também conhecida como Cúpula de Joanesburgo; e a Conferência das Nações Unidas sobre Desenvolvimento Sustentável ou Rio+20, realizada em 2012, no Rio de Janeiro. As convenções ambientais globais tornaram-se espaço de reflexão sobre a importância do ambiente e sua influência na qualidade de vida. Espaço, que em nível mundial, contextualiza o ambiente com questões sociais, políticas e econômicas.

A temática montanha foi ponto focal de documentos importantes elaborados na Rio 92, como a Agenda 21 Global, capítulo 13, denominado "Gerenciamento de Ecossistemas Frágeis: Desenvolvimento Sustentável das Montanhas". Este capítulo é um instrumento político direcionado as esferas nacionais e internacionais. Aborda o desenvolvimento rural, a segurança alimentar, recursos hídricos, diversidade biológica, florestas, mudança climática, cultura, conhecimentos tradicionais, turismo, entre outros, que devem ser considerados quando o tema principal é a montanha. Os principais aspectos do capítulo 13, que são essenciais para o desenvolvimento sustentável dos ambientes de montanha são: conscientizar os povos dessas áreas e apoiar seus esforços para deter o processo de degradação dos seus ecossistemas; e criar instituições responsáveis pelas montanhas, além de formar instituições nacionais, regionais e mundiais que tenham como principal objetivo o desenvolvimento sustentável das montanhas (PRICE; MESSERLI, 2002). Em setembro de 1993, as Nações Unidas designaram a FAO como coordenadora setorial do capítulo 13 da Agenda 21 Global. As responsabilidades atribuídas a FAO foram: motivar e apoiar iniciativas em relação às montanhas; facilitar a cooperação de instituições e manter informada a Comissão das Nações Unidas sobre Desenvolvimento Sustentável (PRICE, 1998).

A Agenda 21 Global é um dos principais resultados da Rio 92. O Brasil, signatário de acordos oriundos dessa conferência, assumiu compromisso de elaborar e implantar sua própria Agenda 21, conforme suas peculiaridades. A incorporação do conceito de desenvolvimento sustentável às ações do governo motivou a criação da "Comissão de Políticas de Desenvolvimento Sustentável - CPDS" e da Agenda 21 Nacional. A Elaboração da Agenda 21 Brasileira (19972002), conduzida pela CPDS, teve como objetivo redefinir o modelo de desenvolvimento do país, introduzindo o conceito de sustentabilidade e qualificando-o com as potencialidades e as vulnerabilidades do Brasil, inclusive no quadro internacional. A Agenda 21 Brasileira procura englobar a complexidade do País e de suas regiões no conceito de sustentabilidade ampliada, a partir de seis temas centrais: agricultura sustentável, cidades sustentáveis, infraestrutura e integração regional, gestão dos recursos naturais, redução das desigualdades sociais, e ciência e tecnologia para o desenvolvimento sustentável (SECRETARIA DO MEIO AMBIENTE DO ESTADO DE SÃO PAULO, 2012). Porém os ecossistemas de montanha, apesar de sua importância, não foram incorporados na Agenda 21 Brasileira. E isto, apesar dos ecossistemas de montanha estar contemplados no capítulo 13 da Agenda 21 Global.

A Convenção sobre Diversidade Biológica (CDB), assim como a Agenda 21 Global, foi um dos principais resultados da Rio 92. A Conferência das Partes (COP) é o órgão supremo decisório no âmbito da Convenção. As reuniões da COP são realizadas a cada dois anos em sistema de rodízio entre os continentes e dá as diretrizes para a CDB. A CDB estabelece regras para uso e proteção da diversidade biológica em cada país signatário como é o caso do Brasil (MINISTÉRIO DO MEIO AMBIENTE, 2013). A biodiversidade das montanhas foi considerada ponto focal pela 
CDB (MARTINELLI, 2007). A COP em sua sétima reunião, na Malásia em 2004, adotou a Decisão VII/27 - Mountain Biological Diversity (CDB, 2004). As metas para as montanhas foram: proteger a diversidade biológica das montanhas; fomentar a utilização sustentável; aperfeiçoar o marco jurídico, institucional, econômico e de políticas; desenvolver trabalhos para a identificação da diversidade biológica das montanhas; aperfeiçoar conhecimentos e métodos de avaliação e supervisão precisas da diversidade biológica das montanhas e desenvolver base de dados; aumentar a pesquisa, cooperação técnica e científica sobre a diversidade biológica das montanhas; aumentar a educação pública sobre o tema; entre outras.

A Cúpula de Joanesburgo foi convocada com o objetivo de estabelecer um plano de ação que acelerasse e fortalecesse a aplicação dos princípios aprovados no Rio de Janeiro. A década que separa as duas conferências confirmou a dificuldade em se executar as recomendações da Rio 92 (LAGO, 2006).

Os mais significativos resultados da Cúpula de Joanesburgo incluem a fixação ou a reafirmação de metas sobre a erradicação da pobreza; água e saneamento; saúde; produtos químicos perigosos; pesca; e biodiversidade. Também a inclusão de dois temas de difícil progresso em inúmeras negociações anteriores, energias renováveis e responsabilidade corporativa; e a decisão política de criação de fundo mundial de solidariedade para erradicação da pobreza. No que se refere aos ambientes de montanha, o parágrafo 42 do Plano de Aplicação das Decisões da Conferência Mundial sobre Desenvolvimento Sustentável, de Joanesburgo, e os Objetivos do Milênio, de 2008, auxiliaram a consolidar a importância da montanha no contexto do desenvolvimento sustentável (NAÇÕES UNIDAS, 2009).

No mesmo ano que ocorreu a Cúpula de Joanesburgo, 2002, a FAO instituiu o "Ano Internacional das Montanhas", e organizou diversos eventos que possibilitaram a consolidação do capítulo 13 da Agenda 21 Global; onde se apoiou a criação de 78 comitês nacionais para realizar atividades no nível de países. Além da criação dos comitês, também se fortaleceram associações interessadas em questões relacionadas às montanhas. $\mathrm{O}$ ponto culminante do "Ano Internacional das Montanhas - 2002" foi a criação da "Alianza para las Montañas" na Cúpula de Joanesburgo em 2002. "Alianza para las Montañas" congrega mais de 160 participantes, entre governos, organizações não governamentais (ONGs) e instituições governamentais. A sede é na FAO (Itália) e tem escritórios no Canadá, Peru, Nepal e Áustria. Seu principal objetivo é melhorar a qualidade de vida das populações que vivem nas regiões montanhosas e conservar essas áreas (NAÇÕES UNIDAS, 2009).

Dez anos após a Cúpula de Joanesburgo se realizou no Rio de Janeiro, mais uma convenção ambiental global, denominada Rio+20. Em relatório apresentado na Assembleia das Nações Unidas (2011) colocou-se que a Rio+20, constituiria oportunidade propicia para se colocar o desenvolvimento sustentável dos ambientes de montanha em lugar proeminente na agenda mundial, considerando-se a mudança climática, crescentes desastres naturais, escassez de água, desertificação e as crises alimentar e energética. Isto ocorreu, já que no documento final aprovado na convenção, "O futuro que queremos", as montanhas ocupam lugar de destaque - artigos 210, 211 e 212.

$\mathrm{O}$ documento "O futuro que queremos" (CNUMAD, 2012) reconhece, entre outros aspectos que: os benefícios derivados das regiões de montanha são essenciais para o desenvolvimento sustentável da humanidade; os ecossistemas de montanha desempenham um papel crucial no fornecimento de água; e que são ecossistemas frágeis e particularmente vulneráveis aos efeitos adversos da mudança climática; desmatamento; mudança do uso da terra; degradação do solo; e desastres naturais. O documento também destaca que as montanhas são, muitas vezes, o lar de diversas sociedades, incluindo povos indígenas e comunidades locais, que desenvolveram usos sustentáveis de recursos provenientes das montanhas. Essas comunidades são, no entanto, muitas 
vezes marginalizadas, sendo necessário contínuo esforço para enfrentar a pobreza, insegurança alimentar e nutricional, exclusão social e degradação ambiental. No documento, os Estados são solicitados a fortalecer a ação cooperativa com efetivo envolvimento e partilha de experiências de todos os interessados no tema montanhas. Além de reforçar mecanismos já existentes, como acordos e centros de excelência para o desenvolvimento sustentável das montanhas, bem como explorar novos arranjos e acordos, quando apropriado. Solicitam-se também maiores esforços para a conservação dos ecossistemas de montanha, incluindo sua biodiversidade, e se encoraja os Estados a adotarem uma visão de longo prazo, com abordagem holística - inclusive incorporando políticas específicas para as montanhas - na estratégia nacional de desenvolvimento sustentável.

Nas convenções ambientais globais anteriormente citadas, os países signatários, inclusive Brasil, aceitaram seguir as orientações de documentos como a Agenda 21 Global; parágrafo 42 do Plano de Aplicação das Decisões da Conferência Mundial sobre Desenvolvimento Sustentável; "O futuro que queremos". Orientações direcionadas ao desenvolvimento sustentável das montanhas, assim como a conservação de ecossistemas montanhosos. Para isto ocorrer são necessárias ações públicas para o cumprimento desses acordos.

\subsection{Ação Pública}

Políticas adequadas são elementos fundamentais para o desenvolvimento sustentável das regiões montanhosas (NAÇÕES UNIDAS, 2007). A seguir será definido o que são "políticas públicas", enfatizando "ação pública", já que este trabalho concentra-se nessa esfera.

Política abrange simultaneamente a esfera da política ("polity"); da atividade política ("politics") e da ação pública ("policies"). A primeira faz a diferença da política e da sociedade civil; sendo que a fronteira entre uma e outra poderá ser tênue, dependendo das épocas e locais analisados. A atividade política refere-se à atividade política em geral, tendo-se como exemplos, debate partidário; competição por nomeações de cargos públicos; as diversas formas de mobilização, entre outros. E por último, o termo que designa o processo pelo qual são elaborados e implementados programas. Estes são dispositivos políticos administrativos coordenados, em princípio, em torno de objetivos explícitos (MULLER; SUREL, 2004).

As políticas públicas podem apresentar caráter: distributivo, regulatório, redistributivo e institucional. Tem-se como exemplos de política pública de caráter distributivo, o crédito rural e programas de equivalência-produto na devolução de empréstimos. Exemplos de políticas públicas de caráter regulatório são os preços mínimos, liberalização ou proibição de produtos importados e a redução/isenção de impostos. As de caráter redistributivo são a reforma agrária e transferência de renda. E por fim, exemplos de políticas públicas de caráter institucional, a estrutura administrativa dos Ministérios e Secretarias do Governo Estadual, e as arenas, como os Conselhos Municipais e Estaduais de Desenvolvimento Rural. As políticas institucionais estão ligadas ao exercício dos direitos dos cidadãos; e com as regras e a organização da prática política e governamental (ROMANO, 2011).

Portanto, teoricamente a política pública denominada "ação pública" ("policies"), são programas onde as ações governamentais podem ser observadas e avaliadas de acordo com seu desempenho pela população. São as políticas onde programas podem repercutir na vida do cidadão de forma concreta. De forma geral, entre as políticas públicas de mais fácil percepção para a sociedade, encontra-se a "ação pública", com seus programas e projetos. 


\subsubsection{Ações públicas brasileiras direcionadas aos ambientes de montanha}

O Brasil possui área representativa de montanhas a nível mundial; é signatário de documentos elaborados em convenções ambientais globais, onde a temática montanha recebe destaque; porém ações públicas, que apresentem como tema focal os ambientes de montanha, não são prioridade no país.

A Comissão Nacional de Biodiversidade (CONABIO) aprovou a Deliberação ${ }^{\circ} 57$ de 28 de outubro de 2008, criando a Câmara Técnica para a elaboração de proposta do Programa Nacional sobre Ecossistemas de Montanha (PNEM) para sugerir, entre outras questões:

"ações para a conservação e o uso sustentável de ecossistemas de montanha; o manejo integrado de fauna e flora conciliado ao manejo integrado de bacias hidrográficas, expansão urbana e agricultura em áreas de montanha, identificando as melhores práticas para evitar a degradação e garantir a estabilidade e a manutenção dos serviços ambientais”.

Como também, "a capacitação de atores envolvidos na conservação e uso sustentável dos ecossistemas de montanhas no Brasil".

Em 2009, a CONABIO indicou o Instituto de Pesquisas Jardim Botânico do Rio de Janeiro Centro Nacional de Conservação da Flora (JBRJ - CNCFlora) para coordenar um seminário para a elaboração do PNEM. O programa foi aprovado na íntegra e por unanimidade em Brasília, na $43^{\mathrm{a}}$ reunião CONABIO, realizada em 2 de março de 2011 (JBRJ, 2011), porém não foi implementado. Mas a aprovação do PNEM pela CONABIO é um marco referencial para as políticas públicas das regiões montanhosas brasileiras.

Apesar de sua importância, no Brasil não existem ações públicas específicas para ambientes de montanha, verificam-se apenas temas transversais a nível federal, regional e estadual que atingem esses ambientes. Têm-se como exemplos, programas direcionados ao turismo rural; Indicação Geográfica; e PSA que atendem indistintamente tanto as terras baixas, quanto as terras altas, não observando as características particulares das montanhas.

Embora não existam programas governamentais específicos para as terras altas brasileiras, a seguir serão apresentados exemplos de ações públicas que podem servir como base de reflexão para políticas públicas direcionadas ao desenvolvimento rural sustentável em ambientes de montanha. Serão destacados exemplos relacionados ao PSA no Brasil.

\subsubsection{Pagamento por serviços ambientais}

A Agência Nacional de Águas (ANA) é uma autarquia, com autonomia administrativa e financeira, vinculada ao Ministério do Meio Ambiente, com a finalidade de implementar, em sua esfera de atribuições, a Política Nacional de Recursos Hídricos, integrando o Sistema Nacional de Gerenciamento de Recursos Hídricos. A ANA foi criada pela Lei Federal $\mathrm{n}^{\mathrm{0}}$ 9.984/2000 e regulamentada pelo Decreto Federal $n^{\circ} 3.692 / 2000$ (ANA, 2013). A ANA desenvolve o Programa Produtor de Água a nível nacional. Idealizado em 2001, o objetivo do programa é estimular a política de PSA através de projetos voltados à proteção de recursos hídricos com foco na conservação do solo, propiciando dessa forma a melhoria da qualidade, ampliação e regularização da oferta de água em bacias hidrográficas estratégicas para o Brasil. Nas sub-bacias são elaborados arranjos locais, com objetivo de criar um mercado para o pagamento pelos serviços ambientais. Nesses arranjos são identificados aqueles que se beneficiam dos serviços, bem como os provedores de serviços ambientais; os que se beneficiam devem estar dispostos a contribuir no pagamento para a conservação do solo e da água; e os provedores de serviços ambientais, estarem dispostos a dar 
continuidade a esses serviços originários em suas propriedades, mediante pagamento de incentivos financeiros.

O público alvo do Programa são produtores rurais, que por adesão voluntária ao programa, adotem manejo conservacionista do solo e da água, tais como: construção de terraços e bacias de infiltração; readequação de estradas vicinais; recuperação e proteção de nascentes; reflorestamento de APP e reserva legal; saneamento ambiental, entre outros. O Programa Produtor de Água ocorre em parceria com Comitês de Bacias Hidrográficas (CBH); Estados e Municípios; Organizações Não Governamentais; empresas de saneamento e de geração de energia elétrica; e agentes financeiros. Remunerando os participantes conforme benefícios gerados em suas propriedades rurais, além de contemplar os participantes com a marca "Produtor de Água" (ANA, 2013).

Verificam-se exemplos de projetos do Programa Produtor de Água em: Extrema em Minas Gerais; Bacia Hidrográfica do Piracicaba, Capivari e Jundiaí (BH PCJ) em São Paulo; Produtor no Espírito Santo; Pipiripau no Distrito Federal; Apucarana no Paraná; Guandu no Rio de Janeiro; Camboriú em Santa Catarina e Guariroba no Mato Grosso do Sul. Em 2012 iniciou-se o processo de licitação para implantação do Programa Produtor de Águas na bacia hidrográfica do alto curso do rio Macaé no Estado do Rio de Janeiro (CBH MACAÉ E OSTRAS, 2012).

O Programa, iniciado em 2005, em Extrema ganhou repercussão a nível nacional e internacional, recebendo vários prêmios, entre eles, em 2013, o Prêmio Internacional de Dubai para Boas Práticas. Em Extrema os parceiros da ANA para a implantação do Programa foram: Prefeitura Municipal de Extrema, The Nature Conservancy, Instituto Estadual de Florestas (IEF) e Governo do Estado de Minas Gerais (ANA, 2013). O município de Extrema localiza-se no extremo sul de Minas Gerais, integrando a BH PCJ, através da sub-bacia dos rios Jaguari e Jacareí. Esta sub-bacia é responsável por $22 \mathrm{~m}^{3} / \mathrm{s}$, dos $33 \mathrm{~m}^{3} / \mathrm{s}$, de água destinada ao abastecimento da região metropolitana de São Paulo, via Sistema Cantareira, beneficiando assim, aproximadamente, nove milhões de pessoas (KFOURI; FAVERO, 2011).

O município de Rio Claro, estado do Rio de Janeiro, através de parceria entre o Instituto Terra, o Comitê da Bacia Hidrográfica do Rio Guandu, a ONG internacional TNC (The Nature Conservancy) e os governos municipal e estadual viabilizou o programa Produtores de Água e Floresta que tem por objetivo remunerar proprietários rurais pelas práticas de restauração e conservação de florestas, principalmente aqueles situados em cabeceiras e margens de rios, visando à proteção e manutenção da Bacia do Rio Guandu, responsável pelo abastecimento de água de aproximadamente sete milhões de pessoas na região metropolitana da cidade do Rio de Janeiro (DIÁRIO DE TERESÓPOLIS, 2010).

Vários estados e municípios estão implantando o PSA e promulgando legislação pertinente ao tema. O estado do Amazonas implantou o programa Bolsa Floresta, que prevê o PSA às comunidades tradicionais das Unidades de Conservação pelo uso sustentável, conservação e proteção dos recursos naturais, bem como incentivo a políticas voluntárias de redução do desmatamento. Em Montes Claros, Minas Gerais os produtores rurais que conservam as APPs e a reserva legal recebem ecocréditos para pagarem impostos municipais e serviços que a prefeitura poderá prestar como capina e horas de máquina (VILAR, 2009).

O Comitê da Bacia Hidrográfica Lagos São João, no Estado do Rio de Janeiro, através do Fundo de Boas Práticas Socioambientais em Microbacias (Funboas), fornece equipamentos e mudas para pequenos e médios produtores rurais que desenvolvam práticas socioambientais em suas propriedades (COMITÊ DE BACIA LAGOS SÃO JOÃO, 2010). O Espírito Santo promulgou a Lei $\mathrm{n}^{\circ}$ 8.995/2008 (ESTADO DO ESPÍRITO SANTO, 2008) onde delibera que parte dos royalties do 
petróleo, do gás natural e do setor elétrico, multas ambientais, do orçamento público municipal, estadual e federal; e de doações; e transferências, serão destinadas ao PSA aos produtores rurais.

No Estado do Rio de Janeiro, o decreto estadual $\mathrm{n}^{\circ} 42.029 / 2011$ estipula que os investimentos do programa PSA deverão priorizar as áreas rurais e de mananciais de abastecimento público, observados critérios a serem aprovados pelo Conselho Estadual de Recursos Hídricos. O Decreto também considera a necessidade de promoção da integridade e conservação ambiental das bacias hidrográficas, com inclusão social da população rural em situação de vulnerabilidade e da melhoria das condições de uso e ocupação do solo em áreas relevantes para a conservação dos recursos naturais (ESTADO DO RIO DE JANEIRO, 2011).

A Lei Federal $n^{0}$ 12.651/2012 (BRASIL, 2012) em capítulo específico sobre Programa de Apoio e Incentivo à Preservação e Recuperação do Meio Ambiente, inclui em suas linhas de ação o:

"pagamento ou incentivo a serviços ambientais como retribuição, monetária ou não, às atividades de conservação e melhoria dos ecossistemas e que gerem serviços ambientais tais como, isolada ou cumulativamente:

a) o sequestro, a conservação, a manutenção e o aumento do estoque e a diminuição do fluxo de carbono;

b) a conservação da beleza cênica natural;

c) a conservação da biodiversidade;

d) a conservação das águas e dos serviços hídricos;

e) a regulação do clima;

f) a valorização cultural e do conhecimento tradicional ecossistêmico;

g) a conservação e o melhoramento do solo;

h) a manutenção de Áreas de Preservação Permanente, de Reserva Legal e de uso restrito;"

Os incentivos as práticas conservacionista do solo e da água, como já ocorre no Programa Produtor de Águas, são fundamentais em programas de pagamento por serviços ambientais realizados em ambientes de montanha. Devido ao relevo, solos rasos e variabilidade geológica, as regiões montanhosas podem tornar-se suscetíveis sem manejo adequado, podendo ocorrer deslizamentos e escorregamentos. Nesse contexto, o planejamento ambiental das unidades produtivas torna-se ferramenta estratégica para manter a capacidade de sustentação dos agroecossistemas e a conservação dos serviços ecossistêmicos. Neste modelo, em programas de PSA, incentivo a práticas agroecológicas poderão ser contempladas. A agroecologia é uma ciência que resgata o conhecimento agrícola tradicional, que se encontra adaptado às condições ambientais (ASSIS, 2002). O agroecossistema é a unidade fundamental dessa ciência, nos quais os ciclos minerais, as transformações energéticas, os processos biológicos e as relações socioeconômicas são vistas e analisadas em seu conjunto. Sob o ponto de vista da pesquisa agroecológica, o objetivo é aperfeiçoar o agroecossistema como um todo; o que significa a necessidade de uma maior ênfase no conhecimento, na análise e na interpretação das complexas relações existentes entre as pessoas, os cultivos, o solo, a água e os animais (ALTIERI, 1999). A agroecologia considera a complexidade dos ecossistemas e, no caso dos ambientes de montanha, que apresentam características tão marcantes, como a altitude e o relevo; essa ciência é importante para que a agricultura esteja em equilíbrio com o ambiente. Por isso, as práticas agroecológicas podem ser consideradas em ações públicas direcionadas ao PSA em ambientes de montanha. 


\section{CONSIDERAÇÕES FINAIS}

Apesar da grande extensão que as terras altas ocupam no território brasileiro, as organizações governamentais, de forma geral, não perceberam a importância de trabalhar os ambientes de montanha em um contexto integrado, criando condições para que as populações que vivem em áreas de montanhas possuam qualidade de vida, assim como as comunidades das terras baixas que dependem de recursos fornecidos pelas terras altas, como, por exemplo, a água. Isto apesar do Brasil ser signatário de importantes documentos como Convenção sobre Diversidade Biológica (Decisão VII/27 - Mountain Biological Diversity) e a Agenda 21 Global (capítulo 13: "Gerenciamento de Ecossistemas Frágeis: Desenvolvimento Sustentável das Montanhas").

O discurso do governo brasileiro, quando se relaciona os documentos provenientes das convenções ambientais globais, é antagônico as suas ações; já que ações públicas não foram direcionadas ao desenvolvimento sustentável dos ambientes de montanha brasileiros. Nas arenas de poder a nível nacional pouco se realizou frente às necessidades específicas das terras altas, inclusive não se implantando o PNEM.

No Brasil são necessários programas e projetos específicos para as características encontradas nos ambientes de montanha brasileiros. Mas já existem trabalhos bem sucedidos em ambientes de montanha, como programas de PSA, que podem servir como objetos de análise e reflexão, e também como projetos pilotos, a serem adequados à realidade das terras altas brasileiras. Ações públicas de PSA poderão incentivar o planejamento ambiental das unidades produtivas, incluindo práticas agroecológicas em ambientes de montanha, promovendo sua sustentabilidade.

\section{REFERENCIAS}

ALIANZA PARA LAS MONTAÑAS. Alianza para las Montañas. 2010. Disponível em < http://www.alianzamontanas.org/default.asp> Acesso em: 20 abril de 2010.

ALTIERI, Miguel A. Agroecologia: bases científicas para una agricultura sustentable. $4^{\text {a }}$ ed. Montevideo. 1999. $338 \mathrm{p}$.

ANA. 2013. Programa Produtor de Água. Disponível em: http://produtordeagua.ana.gov.br// Acesso em: 28 jun. 2013.

ASSIS, Renato Linhares de. Agroecologia no Brasil: análise do processo de difusão e perspectivas. 2002.150 p. Tese (Doutorado em Economia Aplicada), Universidade Estadual de Campinas, Campinas.

BOEIRA, Sérgio Luís. Resenha de Saber Ambiental de Henrique Leff. In: Ambiente \& Sociedade, vol. V, nº $10,2002$. p.1-4. Disponível em < http://www.scielo.br/pdf/asoc/n10/16891.pdf > Acesso em: 26 ago. 2011.

BRAILOVSKY, Antonio Helio; FOGUELMAN, Dina. Memória verde. História Ecológica de la Argentina. Editorial Sudamericana. Buenos Aires. $7^{\text {a }}$ Edición. Septiembre de 1997. 375p.

BRASIL. Lei $\mathbf{n}^{\mathbf{0}} \mathbf{1 2 . 6 5 1}$ de 25 de maio de 2012. Dispõe sobre a proteção da vegetação nativa; altera as Leis $\mathrm{n}^{\text {os }} 6.938$, de 31 de agosto de 1981, 9.393, de 19 de dezembro de 1996, e 11.428, de 22 de dezembro de 2006; revoga as Leis ${ }^{\text {os }}$ 4.771, de 15 de setembro de 1965, e 7.754, de 14 de abril de 1989, e a Medida Provisória no 2.166-67, de 24 de agosto de 2001; e dá outras providências. Disponível em: <http://www.planalto.gov.br/ccivil_03/_Ato20112014/2012/Lei/L12651.htm>. Acesso em: 25 ago. 2012.

CARNEIRO, Maria José. Ruralidade: novas identidades em construção. In: Estudos Sociedade e Agricultura (UFRRJ), Rio de Janeiro, v. 11, p. 53-75, 1998. Disponível em: http://r1.ufrrj.br/esa/art/199810-053-075.pdf Acesso em: 28 jun. 2013.

CBH MACAÉ E OSTRAS, 2012. Programa Produtor de Água CBH-Macaé e das Ostras. Disponível em: <http://www.cbhmacaeostras.eco.br/>. Acesso em: 6 set. 2013.

CDB. COP 7Decision VII/27 - Mountain biological diversity. Kuala Lumpur, Malasia, 09 - 20 de fevereiro de 2004. Disponível em <http://www.cbd.int/decision/cop/?id=7764 > Acesso em: 18 dez. 2010. 
CNUMAD. O futuro que queremos. 2012. Disponível em: <http://www.rets.org.br/sites/default/files/O-Futuro-quequeremos1.pdf >. Acesso em: 28 jun. 2013.

COMISSÃO MUNDIAL SOBRE MEIO AMBIENTE E DESENVOLVIMENTO. Nosso Futuro Comum. $2^{\mathrm{a}}$ ed. Rio de Janeiro: Editora da Fundação Getúlio Vargas, 1991.

COMISSÃO NACIONAL DE BIODIVERSIDADE. Deliberação n ${ }^{\circ} \mathbf{5 7}$ de 28 de outubro de 2008. Dispõe sobre a criação da Câmara Técnica Temporária sobre Ecossistemas de Montanha. Disponível em <http://www.mma.gov.br/index.php?ido=conteudo.monta\&idEstrutura=15\&idConteudo=678> Acesso em: 14 out. 2010 .

COMITÊ DE BACIA LAGOS SÃO JOÃO. Fundo de boas práticas socioambientais em microbacias - Funboas. 2010. Disponível em:<http://www.lagossaojoao.org.br/FUNBOAS.pdf>. Acesso em: 14 mar. 2012.

CORREA, Heitor Delgado. A singularidade do ambiente e os fundamentos jurídicos e extrajurídicos para a construção de uma justiça ambiental. 2008. 156 p. Dissertação (Mestrado em Direito) - Universidade Estácio de Sá, Rio de Janeiro.

CRESCENTE FÉRTIL. As Montanhas no Território Brasileiro. 2002. Disponível em <http://www.montanhasbrasil.org.br/territorio_mont.htm > Acesso em: 10 mai. 2010.

DIÁRIO DE TERESÓPOLIS, O. Palestras sobre pagamento por serviços ambientais. Disponível em: <http://www.odiariodeteresopolis.com.br/leitura noticias.asp?IdNoticia=15801 >. Acesso em: 03 dez. 2010.

DULLEY, Richard Domingues. Noção de natureza, ambiente, meio ambiente, recursos ambientais e recursos naturais. In: Agricultura em São Paulo, São Paulo, v. 51, n. 2, p. 15-26, $2004 . \quad$ Disponível em http://www.iea.sp.gov.br/out/publicacoes/pdf/asp-2-04-2.pdf Acesso em: 26 set. 2011.

ESTADO DO ESPÍRITO SANTO. Lei $\mathbf{n}^{\mathbf{0}} \mathbf{8 . 9 6 0 / 0 8}$ de 18 de julho de 2008. Dispõe sobre a criação do Fundo Estadual de Recursos Hídricos do Espírito Santo - Fundágua. Vitória- ES: Governo do Estado, 2008.

ESTADO DO RIO DE JANEIRO. Decreto n⿳4022.029 de 15 de junho de 2011. Regulamenta o Programa Estadual de Conservação e Revitalização de Recursos Hídricos - PROHIDRO, previsto nos artigos $5^{\circ}$ e 11 da Lei n³.239, de 2 de agosto de 1999, que instituiu a Política Estadual de Recursos Hídricos, e dá outras providências.

GIL, A. C. Métodos e técnicas de pesquisa social. $6^{\text {a }}$ ed. - $3^{\text {a }}$ reimpr. - São Paulo: Ed. Atlas, 2010. 200p.

JBRJ. CONABIO aprova Programa de Conservação de Ecossistemas de Montanhas. 2011. Disponível em: < http://www.jbrj.gov.br/materias/11_03_2011\%281\%29.html > Acesso em: 21 mai. 2011.

KAPOS et al. Defining mountain regions. 2000. In: UNEP-WCMC (World Conservation Monitoring Centre), 2002: Mountain Watch: environmental change \&sustainable development in mountains. Cambridge, UK. Disponível em www.unep-wcmc.org/mountains/mountain_watch/pdfs/ Acesso em: 17 ago. 2010.

KAPOS et al. Defining mountains by topography only. 2000 In: Millenium Ecosystem Assessment. Ecosystems and human well-being: Mountain Systems. Washington, DC: Island Press and World Resources Institute, 2005. Disponível em <http://www.fao.org/forestry/12480-0ace03c1c3b00d717817f18379f9414e.pdf> Acesso em: 28 ago. 2010.

KFouri, A.; FAVero, F. Projeto Conservador das Águas Passo a Passo: Uma Descrição Didática sobre o Desenvolvimento da Primeira Experiência de Pagamento por uma Prefeitura Municipal no Brasil/Brasília, DF: The Nature Conservancy do Brasil, 2011. 60 p.

LAGO, André Aranha Corrêa do. Estocolmo, Rio e Joanesburgo. O Brasil e as três conferências ambientais das Nações Unidas. Fundação Alexandre de Gusmão. Brasília. 2006. 274p.

MARTINELLI, Gustavo. Mountain Biodiversity in Brazil. In: Revista Brasileira de Botânica. V.30, n.4, p.587-597, out.-dez. 2007. Disponível em <www.scielo.br/pdf/rbb/v30n4/04.pdf > Acesso em: 09 nov. 2009.

MATIAS, Hugo Juliano Duarte; PINHEIRO, José Queiroz. Desenvolvimento sustentável: Um discurso sobre a relação entre desenvolvimento e natureza. In: Psicologia \& Sociedade; 20 (1): 134-143, 2008.

MESSERLI, Bruno; DROZ, Marcel; GERMANN, Peter. Las montañas torres de água. In: Revista Ciencias. № 72 , octubre - diciembre 2003 p.4 - 13. Facultad de Ciencias de laUniversidad Nacional Autónoma de México. Disponível em < http://www.ejournal.unam.mx/contenido.html?r=5\&v=S/V\&n=072 >Acesso em: 29 jul. 2011.

MILLENIUM ECOSYSTEM ASSESSMENT. Ecosystems and human well-being: Mountain Systems. Washington, DC: Island Press and World Resources Institute, 2005. Disponível em <http://www.fao.org/forestry/124800ace03c1c3b00d717817f18379f9414e.pdf> Acesso em: 28ago. 2010. 
MINISTÉRIO DO MEIO AMBIENTE. Convenção da Diversidade Biológica. 2013. Disponível em: http://www.mma.gov.br/biodiversidade/convencao-da-diversidade-biologica Acesso em: 28 jun. 2013.

MULLER, Pierre; SUREL, Yves. A análise das políticas públicas. 2 2a edição. Pelotas: Educat, 2004. 156p.

NAÇÕES UNIDAS. Agenda 21. 1992: Rio de Janeiro. Disponível em <http://www.mma.gov.br/sitio/index.php?ido=conteudo.monta\&idEstrutura=18\&idConteudo=575\&idMenu=9065 > Acesso em: 25 ago. 2010.

NAÇÕES UNIDAS. Desarrollo sostenible de la montaña. Asamblea General. A/60/309. 29 de agosto de 2005. Disponível em < http://daccess-dds-ny.un.org/doc/UNDOC/GEN/N05/475/13/PDF/N0547513.pdf?OpenElement> Acesso em: 02 jul. 2010.

NAÇÕES UNIDAS. Desarrollo sostenible: desarrollo sostenible de las regiones montañosas. Asamblea General. A/C.2/62/L.18/Rev.1. 5 de diciembre de 2007. Disponível em <http://daccess-ddsny.un.org/doc/UNDOC/LTD/N07/628/63/PDF/N0762863.pdf?OpenElement> Acesso em: 02 jul. 2010.

NAÇÕES UNIDAS. Desarrollo sostenible de las regiones montañosas. Asamblea General. A/64/222. 3 de agosto de 2009. Disponível em <http://www.un.org/es/comun/docs/?symbol=A/64/222 > Acesso em: 02 jul. 2010.

NAÇÕES UNIDAS. Desarrollo sostenible: desarrollo sostenible de las regiones montañosas.Sexagésimo sexto período de sesiones. Tema 19 idel programa provisional: 11 de agosto de 2011. Disponível em: < http://www.yachaywasi-ngo.org/SG_MTN11s.pdf> Acesso em: 17 fev. 2012.

PNUD. Objetivos de desenvolvimento do milênio. 2013. Disponível em: 〈http://www.pnud.org.br/ODM.aspx>. Acesso em: 28 jun. 2013.

PRICE, Martin. Las montañas: ecosistema de importancia mundial. Unasylva. $\mathrm{n}^{\circ} 195$. Vol. 49. 1998. Disponível em <http://www.fao.org/docrep/w9300s/w9300s03.htm\#TopOfPage> Acesso em: 27 nov. 2010.

PRICE, Martin. MESSERLI, Bruno. Fostering sustainable mountain development: from Rio to the International Year of Mountains, and beyond. In: Unasylva n⿳208. Ano 2002. Disponível em: http://www.fao.org/docrep/004/y3549e/y3549e05.htm Acesso em: 28 jun. 2013.

ROMANO, Jorge O. Redes de política pública na trajetória do setor público agrícola brasileiro. In: BONNAL, Philippe; LEITE, Sergio Pereira (Org.). Análise comparada de políticas agrícolas: uma agenda em transformação. Rio de Janeiro: Mauad X. 2011. 392 p.

SACHS, Ignacy. Estratégias de transição para o século XXI. In: BURSZTYN, Marcel (org.). Para pensar o desenvolvimento sustentável. Editora Brasiliense. 161p. 1993.

SECRETARIA DO MEIO AMBIENTE DO ESTADO DE SÃO PAULO. 2012. O que é Agenda 21? Disponível em: <http://www.ambiente.sp.gov.br/agenda21.php > Acesso em: 12 jan. 2012.

UNEP-WCMC (World Conservation Monitoring Centre), 2002: Mountain Watch: environmental change \& sustainable development in mountains. Cambridge, UK. Disponível em www.unepwcmc.org/mountains/mountain_watch/pdfs/ Acesso em: 17 ago. 2010.

VEIGA, José Eli da. O Prelúdio do Desenvolvimento Sustentável. In: Centro Acadêmico da Faculdade de Economia Administração e Contabilidade da USP (org.). Economia Brasileira: Perspectivas do Desenvolvimento, pp. 243-266 (2005). Disponível em: <http://www.faccamp.br/apoio/MauricioErnica/Jose_Eli_da_Veiga_Preludio_do_desenvolvimento_sustentavel.pdf〉. Acesso em: 17 fev. 2012.

VILAR, Mariana Barbosa. Valoração econômica de serviços ambientais em propriedades rurais. 2009.146 p. Dissertação (Mestrado em Ciência Florestal) - Universidade Federal de Viçosa, Viçosa. Disponível em: <http://alexandria.cpd.ufv.br:8000/teses/ciencia\%20florestal/2009/220743f.pdf > Acesso em: 15 set. 2013.

Parte integrante da Tese da primeira autora. Versão preliminar foi apresentada no X Encontro da Sociedade Brasileira de Economia Ecológica, setembro de 2013. 